\title{
MODELING NIGERIA CRUDE OIL PRODUCTION AND PRICE VOLATILITY USING MULTIVARIATE GENERALIZED AUTOREGRESSIVE CONDITIONAL HETEROSCEDASTICITY MODELS
}

\author{
Usoro Anthony E. and Ekong Akaniynene \\ Department of Statistics, Akwa Ibom State University, Mkpat Enin, Akwa Ibom State, \\ Nigeria. \\ Email: anthonyusoro@aksu.edu.ng
}

Cite this article:

Usoro A.E., Ekong A. (2022),

Modeling Nigeria Crude Oil

Production and Price

Volatility Using Multivariate

Generalized Autoregressive

Conditional Heteroscedasticity

Models. African Journal of

Mathematics and Statistics

Studies 5(1), 33-54. DOI:

10.52589/AJMSS-L4FI9DW6

\section{Manuscript History}

Received: 24 Dec 2021

Accepted: 25 Jan 2022

Published: 15 Feb 2022

Copyright $\odot 2022$ The Author(s). This is an Open Access article distributed under the terms of Creative Commons AttributionNonCommercial-NoDerivatives 4.0 International (CC BY-NC-ND 4.0 ), which permits anyone to share, use, reproduce and redistribute in any medium, provided the original author and source are credited.
ABSTRACT: Modelling of Nigeria's Crude Oil Production and Price Volatilities was the major focus of this paper. The paper investigated the stationarity of the multivariate time series positive definiteness property, and the results revealed the stationarity of the multivariate time series. Special classes of MARCH and MGARCH models were fitted to the crude oil price and production volatilities, and MARCH [p (3,1)] outperformed other models with the aid of model selection criteria. The research has established interaction and interdependence between the two macroeconomic variables and has also revealed bilateral causality between crude oil production and price. This further substantiates the fact that every regime of oil price shock is tantamount to high variability in production, which, in effect, causes a setback in the economic development of the affected country. Hence, this paper proposes proactive measures that can always guarantee stability in crude oil production whenever the country experiences instability in the oil price in the international market.

KEYWORDS: Oil Price Volatility, Oil Production Volatility, MARCH, MGARCH

MSC 2010 Mathematics Subject Classification Object: 62M10 


\section{INTRODUCTION}

There is no dispute the fact that production quantities and prices of crude oil and gas have a tremendous effect on a country whose economy relies so much on the petroleum sector as a major source of income. On the African Continent, Nigeria is reputed to be the highest producer of raw petroleum resources. This historical record of the country in the exploration business is backdated to the early nineteenth century. As a major contributor to the economic boom and development, it triggers interest and concern from the government, the public, and stakeholders in the petroleum sector, as well as other economic sectors whose sustainability is predicated upon the oil and gas sector. It is not good news for any oil-producing nation when the international oil market experiences dwindling oil prices, which, in a way, has a negative contribution to the crude oil production quantity orchestrated by the low feedback on prices.

Oil exploration activities began in Nigeria in 1937, but the main drilling started in 1951 in Owerri. Oil was discovered in noncommercial quantities at Akata, near Eket, in 1953. Prior to the discovery of oil at Akata, the company had spent around \$6 million on exploratory activities in the country. In the pursuit of commercially available petroleum, Shell-BP found oil in Nigeria in 1956. Other important oil wells discovered during the period were Afam and Bomu in Ogoni territory. Production of crude oil began in 1957, and in 1960 a total of 847,000 tonnes of crude oil was exported. As production continued, many other multinational companies were granted licenses for exploration. These included Mobil in 1955, Tenneco in 1960, Chevron in 1961, Agip in 1962 and Elf in 1962. In the year 2001, the production quantity was an average of 2,200 barrels per day, with slight variations without a negative effect on the economy. It is expected that the industry will continue to be profitable based on an average benchmark oil price of $\$ 50-\$ 60$ per barrel. The steady growth in the sector enkindled hope for the future of the sector and the overall economy of the nation. Sometimes in 2014 and 2015, the petroleum sector experienced intermittent disruption by the protests of Niger Delta militants who agitated for more attention from the federal government to the plight of the region. Fortunately, government proactive efforts to address the agitations of the aggrieved Niger Delta Militants yielded positive results. In 2020, the petroleum sector faced a challenge of a reduction in the quantity of crude oil production and prices. This was as a result of the pandemic (CORONA VIRUS) that is still affecting the world today. The frequent reduction in the quantity and price of crude oil really affected Nigeria's economy because of Nigeria's large dependence on crude oil revenue. It is worth knowing that crude oil, for the last three decades, has been the major source of revenue, energy and foreign exchange for the Nigerian economy. In 2000, oil and gas export earnings accounted for about $98 \%$ and about $83 \%$ of federal government revenue. In the crude oil market, when there is a sharp fall in the international oil price, production quantities will be reduced and this may lead to a corresponding decline in financial receipts, as it was in the early 1980s. These nations are faced with problems that could become a big challenge. The challenge of dwindling production quantities and prices of crude oil constitutes a major concern in

\section{Volatility in Crude Oil Production Quantity and Price}

No dispute the fact that instability in the prices of crude oil is one of the reasons why some oilproducing countries that are principally relying on the sector have been facing serious challenges of economic instability during the regime of international price shocks. The uncontrollable dwindling prices of oil have a feedback effect on the successive production quantities due to unattractive market prices in the regime of oil price fall. It is worth noting that 
Nigeria, being a member of the organization of petroleum exporting countries (OPEC), has no control over its own oil price deciding factors, but could make policies and come up with control measures that would help the free flow of crude oil production, though sometimes natural disasters or man-made attitudes can hamper its production quantity. Other factors that contribute to high variability both in crude oil production and price include demand and supply mechanisms, weather, technology, geopolitics, workers' strikes, oil spills, pipeline vandalism, exchange rates, interest rates, and many others. The interest in production performance is explained by the fact that petroleum products are a major source of financing for Nigeria's budget vis-à-vis the dynamics between quantity and price. The need for bivariate time series analysis, modelling and investigation of the causal relationship between the two economic variables is inevitable, especially when an economy experiences price shocks. What measures price shocks is the variance of the error term from the estimated model. The Volatility measure gives an idea about the variations in crude oil production and prices as an indicator of uncertainties in an oil-producing economy. Despite the fact that research has been carried out on crude oil price volatility using different classical Autoregressive Conditional Heteroskedasticity (ARCH) and Generalized Autoregressive Conditional Heteroskedasticity $(\mathrm{GARCH})$, so far bivariate time series analysis has not been adopted to study crude oil production quantity and price and their volatilities. This work is motivated by the need to carry out bivariate time series analysis to establish feedforward and feedback mechanisms between crude oil production quantity and price, as well as investigate the causal relationship between the two variables on the assumption that the variability in the price of crude oil in Nigeria has an effect on the successive production quantity and vice versa.

\section{LITERATURE REVIEW}

\section{Volatility}

The prices of financial market securities are often shaken by large and time-varying shocks. The time-varying shocks of these price movements are always unpredictable. There are times when the economy faces significantly high and low crude oil prices, thereby resulting in volatility. Within these periods, volatility seems to be positively autocorrelated with high amplitudes likely followed by high amplitudes and low amplitudes followed by low amplitudes. This observation, which is particularly relevant for high-frequency data such as daily stock market returns, implies that the conditional variance of the one-period forecast error is no longer constant (homoscedastic), but time-varying (heteroskedastic). This insight motivated Engle (1982) and Bollerslev (1986) to model the time-varying variance. A period in which the financial data earlier mentioned exhibits wide swings for an extended time period followed by a period of comparative tranquillity is often referred to as VOLATILITY CLUSTERING, according to Darmoder and Porter (1997).

\section{Stationarity of Time Series}

Data that was originally not stationary can be made to be stationary with some time-series operators or techniques. These may include the application of different operators such as if or for a non-seasonal time series process, if for a seasonal time series, taking the logarithm or square root of the series to stabilize the variance for non-constant variance, etc. The initial process taken to visualize the behaviour of a process is the time graph plotted to display some 
hidden features that characterize the series. A test may also be carried out in order to ascertain the stationarity of the time-series data. The test may include the Unit Root Test, which involves regression, autocovariance autocorrelation, positive definiteness property which is used to ascertain the stationarity of the multivariate time series, and autocovariance structure with the autocorrelation matrix at different time lags. (Engle and Kroner,1995). Patrick (2020) considered power envelop properties for tests against both stationary and explosive alternatives. The study was conducted to check the effect of trends on the non-stationary time series. In multivariate time series, the n-dimensional cross-auto covariance or crossautocorrelation matrix is composed of sub-matrices of individual vector processes with distributed lags. For a cross-autocorrelation matrix to be positive definite, it would be assumed that the individual sub-autocorrelation matrices meet the positive definiteness conditions, which includes their determinants and principal minors, must have positive values. Bollersler et al. (1988) considered the $\mathrm{k}=2 \mathrm{ARCH}$ (1) process and a symmetric positive definite matrix of cross-covariances. Kiyang and Shahabi (2005) investigated the stationarity of multivariate time series for correlation-based data analysis using a method called Corona and eros. Corona is a supervised feature subset election technique for multivariate time series data sets. Each multivariate time series data is first represented by correlation coefficients, which are subsequently transformed into vectors. In addition to the investigation into the assumption of positive definiteness of the n-dimensional cross autocovariance matrix, it has become more revealing to investigate the positive definiteness of the sub autocovariance matrices of individual vectors as the components of the cross-covariance and cross-correlation matrix. This is considered as the first step in verifying stationarity property before the larger crosscovariance matrix is investigated, Usoro (2020).

\section{Related Models}

According to Engle (1982), the term ARCH means Autoregressive Conditional Heteroscedasticity, and this comes into play when we decide not to model the level of financial time series but instead focus on their differences. This is one of the reasons why we model variance in financial series data as well as make forecasts, which is very important in many areas where option prices are to be examined, value at risk applies. Therefore, it becomes important to model out of sample forecasting ability as a natural model selection condition for volatility models.

$$
\sigma_{t}^{2}=\alpha_{o}+\sum_{i=1}^{q} \alpha_{i} \varepsilon_{t-i}^{2}
$$

Equation 1 is the ARCH (q) model. The term GARCH, according to Bollerslev (1986), means Generalized Autoregressive Conditional Heteroscedasticity. The GARCH shows that the conditional variance of a stochastic process $\mathrm{X}$ at a time does not only depend on the squared error term in the previous time period as in $(\mathrm{ARCH})$ but also on its conditional lagged variance in the previous time period. Different GARCH models have been used to study the inflation rate using consumer price index volatility.

$$
\sigma_{t}^{2}=\omega+\sum_{i=1}^{p} \alpha_{i} \sigma_{t-i}^{2}+\sum_{j=1}^{q} \beta_{j} \varepsilon_{t-j}^{2}
$$


Equation 2 is the GARCH (p, q) model.

Although the GARCH model has proven useful in capturing the symmetric effect of volatility, it is bedevilled by some limitations, such as the violation of non-negativity constraints imposed on the parameters to be estimated. To overcome these constraints, some extensions of the original GARCH model have been proposed. These include asymmetric GARCH family models such as Exponential GARCH (EGARCH) by Nelson (1991), Power GARCH (PGARCH) by Ding (1993), Glosten-Jagannathan-Runkle (1995), and others. Generalized Autoregressive Conditional Heteroscedasticity (Glosten et al, 1993) models in the asymmetric ARCH process, Threshold GARCH (TGARCH) by Zakoian (1994), Quardratic GARCH, Setana (1995), Generalized Orthogonal GARCH model, Roy (2002), Continuous-time GARCH model: COGARCH, Claudia et al (2004), Spartial. The advantage of these models is on the basis of the understanding that good news is synonymous with positive schocks and bad news, which signifies negative schocks of the same magnitude, has differential effects on the conditional variance.

Engle (1982) introduced Multivariate Autoregressive Conditional Heteroskedasticity (MARCH) as a multivariate analogous to ARCH. The multivariate form of GARCH is MGARCH (Bollerslev et al., 1998). These multivariate extensions of both ARCH and GARCH models may also be well explained in ways similar to vector autoregressive (VAR) and vector autoregressive moving average (VARMA) models. The MARCH and MGARCH models are presented as

$$
\begin{aligned}
& \sigma_{i t}^{2} \\
& =\alpha_{i} \\
& +\sum_{i=1}^{a} \sum_{j=1}^{b} \sum_{k=1}^{q} \alpha_{i j . k} \varepsilon_{i t-k}^{2} \\
& \sigma_{i t}^{2}=\alpha_{i}+\sum_{i=1}^{a} \sum_{j=1}^{b} \sum_{k=1}^{p} \alpha_{i j . k} \sigma_{i t-k}^{2}+\sum_{v=1}^{c} \sum_{s=1}^{d} \sum_{l=1}^{q} \beta_{v s . l} \varepsilon_{i t-l}^{2}
\end{aligned}
$$

where, $\sigma_{i t(i=1, \ldots, a)}^{2}$ is the conditional variance, $\sigma_{i t-k(i=1, \ldots, a)}^{2}$ are lagged terms of the conditional variance with the associated parameters $\alpha_{i j . k(i=1, \ldots, a ; j=1, \ldots, b ; k=1, \ldots, p)}, \varepsilon_{i t-l(i=1, \ldots, a)}^{2}$ are lagged terms of the squared error with the associated parameters $\beta_{v s . k(v=1, \ldots, c ; s=1, \ldots, d ; l=1, \ldots, q)}, p$ and $q$ are the orders of the autoregressive and moving average components of the MGARCH models respectively. Equations 3 and 4 are $\mathrm{MARCH}$ and MGARCH respectively as multivariate analogues to ARCH and GARCH represent in equations " 1 " and " 2 " above, Usoro (2019)

\section{Empirical Review}

A number of empirical works on volatilities are highlighted in this paper. Bollerslev (1990) used MARCH in modelling coherence in short-run nominal exchange rates. Damoder and Porter (1997) used ARCH and GARCH models to study the US/UK exchange rate and NYSE, which showed that the ARCH (2) model was not significant, which suggested that perhaps a GARCH $(1,1)$ would have been appropriate for the US/UK exchange rate. Different GARCH models have been used to study the inflation rate using consumer price index volatility, especially in finance, even though a number of theoretical issues are still unresolved (Franses 
and McAleer, 2002). Narayan and Narayam (2007) modelled the volatility of daily oil prices using an exponential generalized Autoregressive conditional heteroscedasticity (EGARCH) model. He found out that the asymmetric effect is on the oil price data series. Also, Olowe (2009) studied weekly oil price volatility of all countries' average spot price using EGARCH $(1,1)$ for the periods ranging from January 3, 1997 - March 6, 2009. His findings show that the oil price return series has high persistence of volatility, volatility clustering and asymmetric properties. Tatyana and Marc (2010) investigated the dynamics of oil prices (Brent and WTI crude oil markets) and their volatilities by linking four GARCH related models, which include; GARCH $(1,1)$, GJR-GARCH $(1,1)$, EGARCH $(1,1)$ and APARACH $(1,1)$. The results of this study showed that oil shocks have an impact and there are asymmetric properties to the volatility of the markets under review. Babatunde and Sani (2012). Babatunde and Sani revealed that GARCH $(1,1)$ was adequate for the food consumer price index $(\mathrm{CPI})$, while the asymmetric TGARCH $(1,1)$ provided an appropriate paradigm for headline core CPI. Omotosho and Doguwa (2012) use different GARCH models like GARCH, TGARCH and EGARCH to analyze inflation in Nigeria. Suliman $(2012)$ fitted GARCH $(1,1)$ to the exchange rate volatility of some Arab countries. He made use of both symmetric and asymmetric models to get facts about volatility clustering and the leverage effect of exchange rate returns. Bala and Asemota, (2013) fitted the GARCH model to the exchange rate and Yayah used the GARCH model on the Nigeria stock index. Isenah et al (2013) applied the ARMA-GARCH model to assess the volatility of the Nigerian stock market. From his analysis, he found out that the ARMA $(1,2)-$ GARCH $(1,1)$ model was the best model to be used.

In 2014, Oluwatomisin et al investigated the effect of oil prices, external reserves and interest rates on exchange rate volatility in Nigeria. To make the work easier for him, he used Johnson's co-integration technique. A vector correction mechanism was used to establish a long-run relationship between the variables. From his analysis, he found out that oil price volatility results in exchange rate volatility. He accepted that the variation in oil crude production affects macroeconomic stability. Koima et al (2015) and David and Peter (2016) investigated the Kenyan stock market with the aid of the GARCH model. The results showed evidence of volatility clustering over time. Still on the stock exchange are Roni and Shouyang (2020). Nortey et al (2015) examined the volatility and conditional relationship between inflation rates, exchange rates, and interest rates together with the construction of a model of MGARCH, DCC, and BEKK using a data set of Ghana from January 1990 to December 2013. He found out that the BEEK model was the best-fitted model to use in modelling and forecasting volatility of inflation, exchange rates, and interest rates, whereas the DCC model was good at modelling the conditional and unconditional correlation of inflation and interest rates respectively. The impact of oil price volatility on economic growth was investigated by Ifeanyi and Ayenajeh (2016). Also, Umah et al (2016) examined the Granger Causality test to ascertain unidirectional causality between oil prices and economic growth in Nigeria. Abduchakeem et al (2016), while studying oil price - macroeconomic volatility in Nigeria using the GARCH model of daily, monthly, and quarterly data, revealed that all the macroeconomic variables considered (real gross domestic product, interest rate, exchange rate, and oil price) were highly volatile and that oil prices are a major source of economic volatility in Nigeria. Philip and Adeleke, (2017) investigated the trading volume volatility in Nigeria's banking sector with GARCH $(1,1)$ and BL-GARCH $(1,1)$ as the most appropriate models to be used. Olugbenga and Kehinde (2017) investigated the impact of oil price volatility on investment decision making in marginal fields development in Nigeria. The study also examined the causal relationship between oil price volatility and marginal field investment analysis in Nigeria. The marginal field's crude oil 
production was used as a replacement for investment analysis. The study covers the period ranging from October 2015 to April 2016. The GARCH model, Johansen cointegration, and Granger causality tests were used in estimating the results. The results showed a significant positive relationship between oil price volatility and crude oil production (P 0.05). Emenike, (2017) analyzed and came to the conclusion that there is volatility in oil prices and money market rates, thereby showing evidence of unidirectional volatility spillovers from crude oil prices to the money rate in Nigeria. Bala and Takimolo (2017) used the MGARCH model and its variants to investigate stock return volatility and spillovers in emerging and developed markets. Deebom and Essi (2017) modelled the price volatility of Nigerian Crude Oil markets using the GARCH Model. His results showed that the GARCH $(1,1)$ model gave a better fit than the EGARCH $(1,1)$ model.

Usoro et al (2020) applied the ARCH and GARCH models to model Nigeria's crude oil production volatility series. With the aid of the Akaike information criterion (AIC), Bayesian information criterion (BIC) and Schwarz's information criterion (SIC), two competitive models for modelling crude oil production volatilities were $\operatorname{GARCH}(1,2)$ and $\operatorname{GARCH}(2,1)$ models. The AIC and BIC values of the 2 models placed the GARCH $(1,2)$ model superior to the GARCH $(2,1)$ model in modelling the crude oil production volatility data. Titus and Ahmed (2020) Modeled the Fluctuation of the Price of Crude Oil in Nigeria Using ARCH and ARCHM Models. His findings show that ARCH $(1,1)$ in student's error distribution assumption has a value of (2.056886) with the Akaike information criteria (AIC) of-2.101125 and ARCH-M $(1,1)$ in student's error distribution (2.043333) with the Akaike information criteria (AIC) (2.109268) was chosen as the best fitted symmetric models for estimating crude oil export prices within the sample period.

This paper reviewed empirical work related to the applications of different classes of ARCH and GARCH models. With special reference to Usoro et al (2020) and Titus and Ahmed (2020), this paper considers Bivariate ARCH and GARCH models as special cases of Multivariate $\mathrm{ARCH}$ and GARCH models in modelling the two-time series so as to investigate the feedforward and feedback mechanisms between crude oil production and price as a way to establish and substantiate the claim of interactions and interdependence between the two variables. The outcome of the research is expected to reveal the causal effect of the volatility of one macroeconomic variable on the other.

\section{METHODOLOGY}

The data for this analysis was collected from the Central Bank of Nigeria Statistical Bulletin. The data is monthly crude oil production quantity and price for the period of January 2006 to July 2019. The data is presented in the appendix.

\section{Volatility Measures}

$$
\begin{aligned}
& \text { Given } Y_{t}=\text { crude oil production quantity } \\
& Y_{t}^{*}=\log \log \text { of } Y_{t}, \\
& d Y_{t}^{*}=Y_{t}^{*}-Y_{t-1}^{*}
\end{aligned}
$$




$$
X_{1 t}=d Y_{t}^{*}-d \underline{Y_{t}^{*}}
$$

(6) is the relative change in the crude oil production quantity

(7) is the mean adjusted relative change in the crude oil production quantity. (the return series)

The square of $X_{1 t}$, that is $X_{1 t}^{2}$ is now used as the measure of volatility (Gujarati and Porter 2009)

$$
\begin{gathered}
\text { Similarly, } \\
\text { Given } X_{t}=\text { crude oil price } \\
X_{t}^{*}=\log \log \text { of } X_{t}, \\
d X_{t}^{*}=X_{t}^{*}-X_{t-1}^{*} \\
X_{2 t}=d X_{t}^{*}-\underline{d X_{t}^{*}}
\end{gathered}
$$

(9) is the relative change in the crude oil price

(10) is the mean adjusted relative change in the crude oil price

The square of $X_{2 t}$, that is $X_{2 t}^{2}$ is now used as the measure of volatility (Gujarati and Porter 2009)

\section{Cross-Autocovariances and Cross-Autocorrelations}

In this section, both cross-covariance and cross-correlation will be discussed.

\section{Cross- Autocovariance}

Usoro (2020) presented autocovariance's, cross-autocovariance's, autocorrelation and crossautocorrelation as shown below;

$$
\mathbb{\Gamma}_{i t+k, j t+l}=\left[\begin{array}{ccccc}
\mathbb{\Gamma}_{1 t+k, 1 t+l} & \mathbb{\Gamma}_{1 t+k, 2 t+l} & \mathbb{\Gamma}_{1 t+k, 3 t+l} & \cdots & \mathbb{\Gamma}_{1 t+k, n t+l} \\
\mathbb{\Gamma}_{2 t+k, 1 t+l} & \mathbb{\Gamma}_{2 t+k, 2 t+l} & \mathbb{\Gamma}_{2 t+k, 3 t+l} & \cdots & \mathbb{\Gamma}_{2 t+k, n t+l} \\
\mathbb{\Gamma}_{3 t+k, 1 t+l} & \mathbb{\Gamma}_{3 t+k, 2 t+l} & \mathbb{\Gamma}_{3 t+k, 3 t+l} & \cdots & \mathbb{\Gamma}_{3 t+k, n t+l} \\
\vdots & \vdots & \vdots & \cdots & \vdots \\
\mathbb{\Gamma}_{m t+k, 1 t+l} & \mathbb{\Gamma}_{m t+k, 1 t+l} & \mathbb{\Gamma}_{m t+k, 1 t+l} & \mathbb{\Gamma}_{m t+k, n t+l}
\end{array}\right]
$$

where $i=1, \ldots, m ; j=1, \ldots, n ; k=1, \ldots, r ; l=1, \ldots, s$

Equation 11 is the cross-covariance matrix. 


\section{Autocorrelations and Cross Autocorrelations}

Autocorrelations measure the correlations between the same variables at different lags $\left(X_{i t+k \text { and }} X_{j t}\right.$ or $X_{\text {it and }} X_{j t+l} ; i=j$ at $k=0,1, \ldots, r$ or $\left.l=0,1, \ldots, s\right)$, while CrossAutocorrelations measure correlations between different variables at different lags $\left(X_{\text {it and }} X_{j t}, i \neq j\right.$ at $k=0,1, \ldots, r$ and $\left.l=0,1, \ldots, s\right)$.

In a univariate time, series, autocorrelation is given as

$$
R_{s, t}=\frac{E\left(X_{t}-\mu\right)\left(X_{S}-\mu\right)}{\sigma_{t} \sigma_{s}}
$$

Therefore,

$$
\mathbb{R}_{\text {it }+ \text { k,jt+l}}=\left[\begin{array}{ccccc}
\mathbb{R}_{1 t+k, 1 t+l} & \mathbb{R}_{1 t+k, 2 t+l} & \mathbb{R}_{1 t+k, 3 t+l} & \cdots & \mathbb{R}_{1 t+k, n t+l} \\
\mathbb{R}_{2 t+k, 1 t+l} & \mathbb{R}_{2 t+k, 2 t+l} & \mathbb{R}_{2 t+k, 3 t+l} & \cdots & \mathbb{R}_{2 t+k, n t+l} \\
\mathbb{R}_{3 t+k, 1 t+l} & \mathbb{R}_{3 t+k, 2 t+l} & \mathbb{R}_{3 t+k, 3 t+l} & \cdots & \mathbb{R}_{3 t+k, n t+l} \\
\vdots & \vdots & \vdots & \cdots & \vdots \\
\mathbb{R}_{m t+k, 1 t+l} & \mathbb{R}_{m t+k, 1 t+l} & \mathbb{R}_{m t+k, 1 t+l} & \mathbb{R}_{m t+k, n t+l}
\end{array}\right]
$$

\section{Positive Definiteness of Cross-Auocorrelation as a Test for Stationarity of Crude Oil Quantity and Price.}

The positive definiteness of the autocorrelation matrix requires that all the principal minors of the autocorrelation matrix be greater than zero. Also, the determinant of the autocorrelation matrix is greater than zero, Box and Jenkins (1976).

Given (13) above,

$$
\mathbb{R}_{\text {it+k,jt+l}}=\left[\begin{array}{ccccc}
\mathbb{R}_{1 t+k, 1 t+l} & \mathbb{R}_{1 t+k, 2 t+l} & \mathbb{R}_{1 t+k, 3 t+l} \cdots & \mathbb{R}_{1 t+k, n t+l} \\
\mathbb{R}_{2 t+k, 1 t+l} & \mathbb{R}_{2 t+k, 2 t+l} & \mathbb{R}_{2 t+k, 3 t+l} & \cdots & \mathbb{R}_{2 t+k, n t+l} \\
\mathbb{R}_{3 t+k, 1 t+l} & \mathbb{R}_{3 t+k, 2 t+l} & \mathbb{R}_{3 t+k, 3 t+l} & \cdots & \mathbb{R}_{3 t+k, n t+l} \\
\vdots & \vdots & \vdots & \cdots & \vdots \\
\mathbb{R}_{m t+k, 1 t+l} & \mathbb{R}_{m t+k, 1 t+l} & \mathbb{R}_{m t+k, 1 t+l} & \mathbb{R}_{m t+k, n t+l}
\end{array}\right]
$$

Positive definiteness of $R_{i t+k, j t+l}$ requires that:

(i) The minors of $R_{1 t+k, 1 t+l}, R_{2 t+k, 2 t+l}, R_{3 t+k, 3 t+l}$ and $R_{m t+k, n t+l}$ be greater than zero

(ii) The determinant of $R_{i t+k, j t+l}>0$ 


\section{The March and Mgarch Models}

\section{MARCH Model}

The MARCH (q) for $\sigma_{1 t}^{2}, \sigma_{2 t}^{2} \ldots \sigma_{n t}^{2}$ models are expressed below

$$
\sigma_{i t}^{2}=\alpha_{i}+\sum_{i=1}^{m} \sum_{j=1}^{n} \sum_{k=1}^{q} \alpha_{i j . k} \varepsilon_{i t-k}^{2}
$$

where, $\sigma_{i t}^{2}$ is the conditional variance of the MARCH model, $\varepsilon_{i t}^{2}$ is the squared error term. $\alpha_{i j . k}$ are the parameters of the squared error terms. $i=1,2 \ldots m, j=1,2 \ldots n, k=1,2, \ldots, q$

\section{MGARCH Model}

The MGARCH $(p, q)$ for $\sigma_{1 t}^{2}, \sigma_{2 t}^{2} \ldots \sigma_{n t}^{2}$ models are expressed in matrix form as shown below;

$$
\sigma_{i t}^{2}=\alpha_{i}+\sum_{a=1}^{m} \sum_{b=1}^{n} \sum_{c=1}^{p} \gamma_{a b . c} \sigma_{i t-c}^{2}+\sum_{i=1}^{m} \sum_{j=1}^{n} \sum_{k=1}^{q} \alpha_{i j . k} \varepsilon_{i t-k}^{2}
$$

where $\sigma_{i t}^{2}$ is the conditional variance of the GARCH model, $\varepsilon_{i t}^{2}$ is the squared error term.

$\alpha_{a j . k}$ and $\beta_{v s . l}$ are the parameters of the lagged variance and squared error terms respectively.

$$
i=1,2 \ldots m ; a=1,2 \ldots m ; b=1,2 \ldots n ; c=1,2 \ldots p ; i=1,2 \ldots m ; j=
$$
$1,2 \ldots n ; k=1,2 . . q$

Usoro et al (2019).

\section{Trend Analysis Crude Oil Quantity and Price}

Here, we present trend analyses of the original and return series of crude oil production quantity and price.

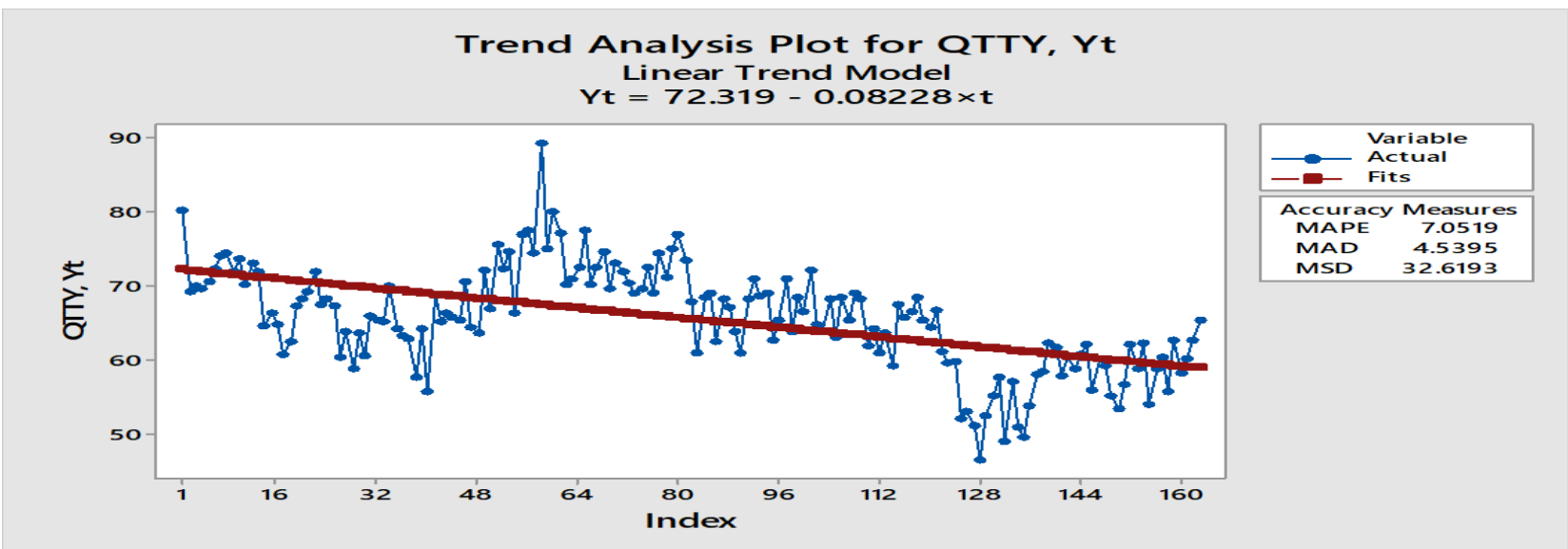

Figure 1: Trend Analysis of Original Crude Oil Production Quantity Data 


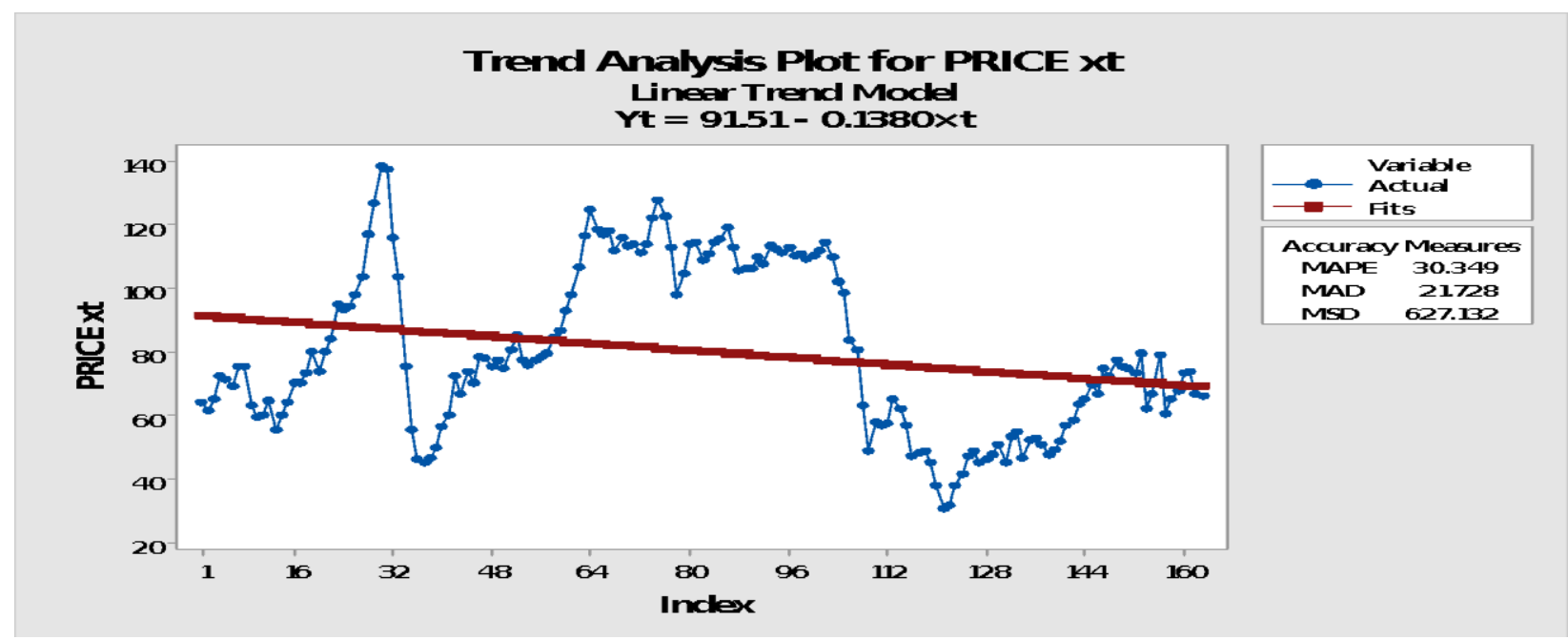

Figure 2: Trend Analysis of Original Crude Oil Price

Figures 1 and 2 display the trend analysis of crude oil production and prices respectively. The graphs show a gradual decrease in crude oil production and prices over time, with the downward trends explained by the falling price of crude oil in the global market between the years 2015 and 2017. The two graphs exhibit almost the same pattern, suggesting bilateral causation between crude oil production and price.

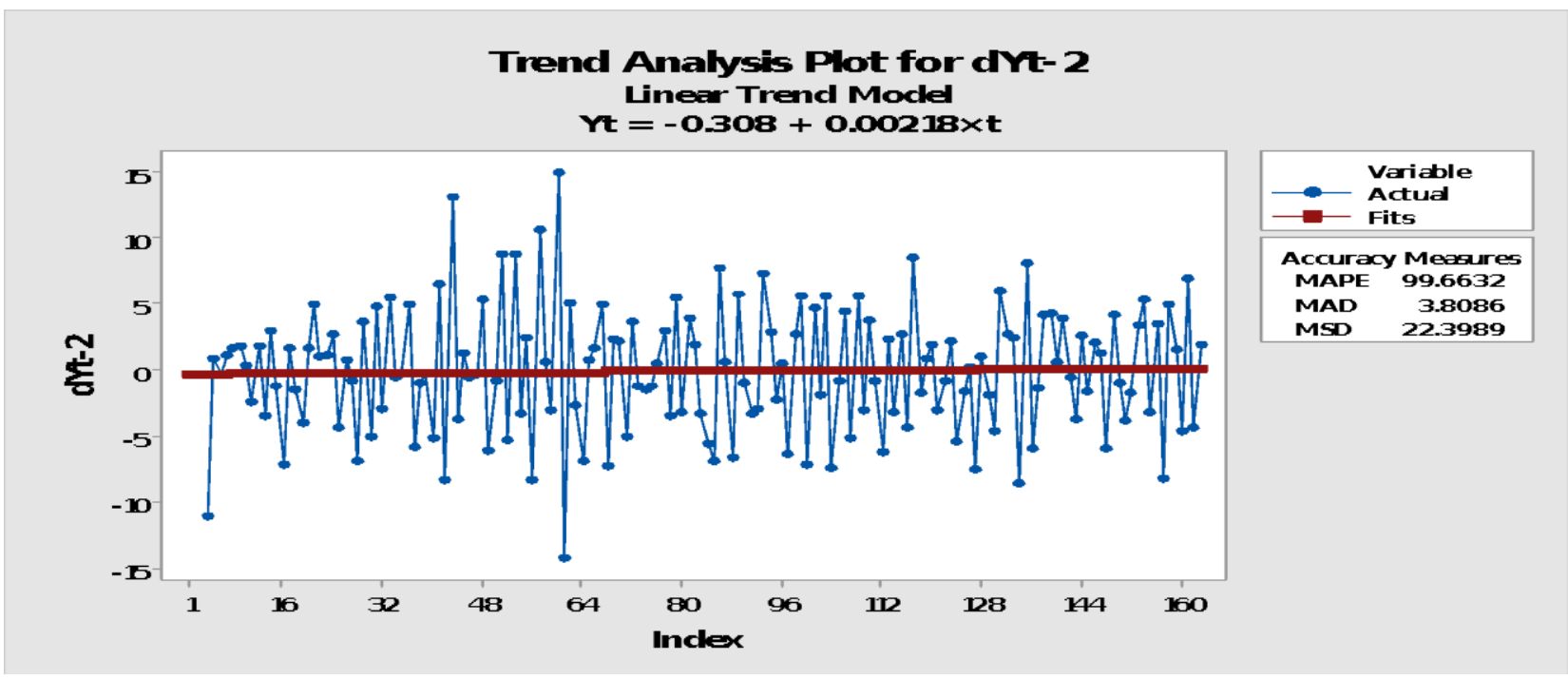

Figure 3: Trend Analysis of the Stationary Crude Oil Production Quantity Data 


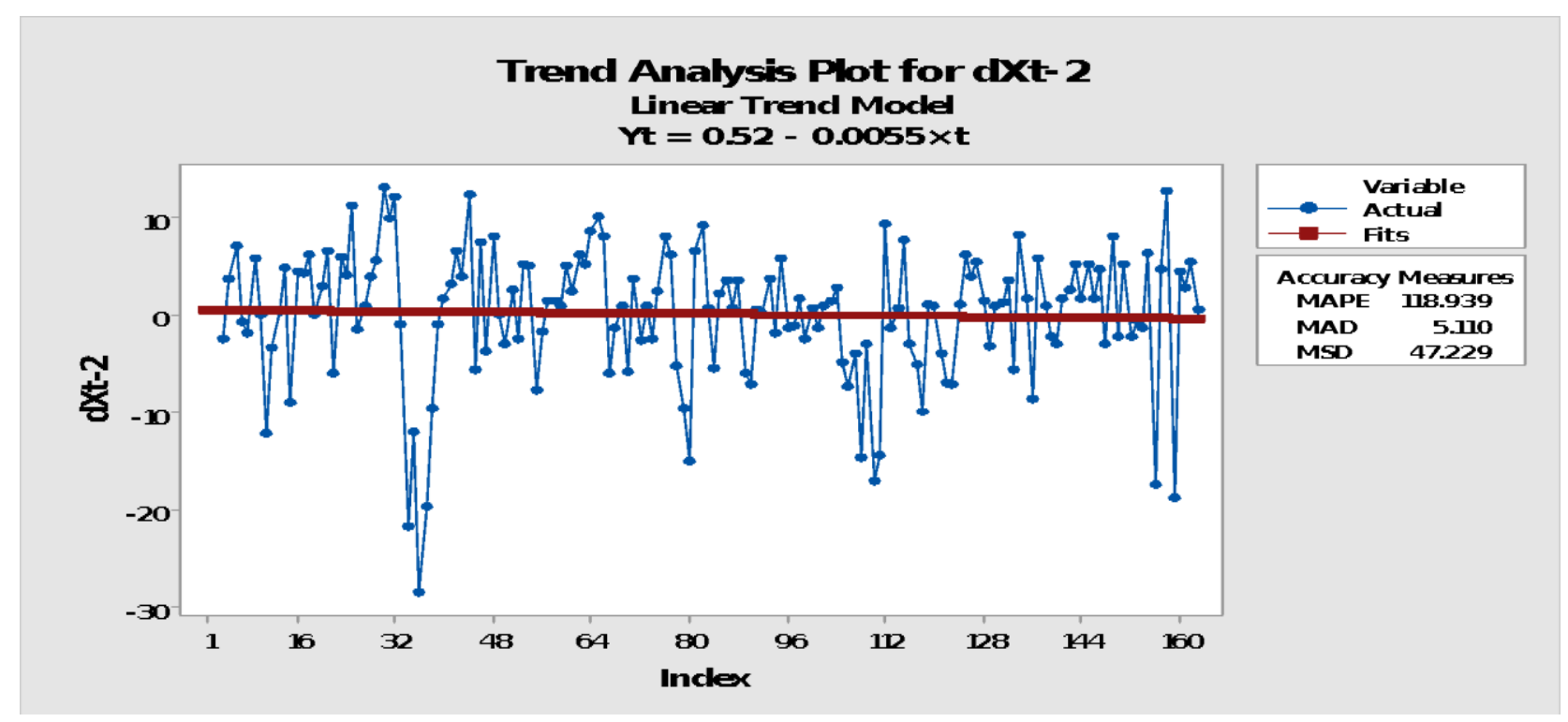

Figure 4: Trend Analysis of the Stationary Crude Oil Price Data

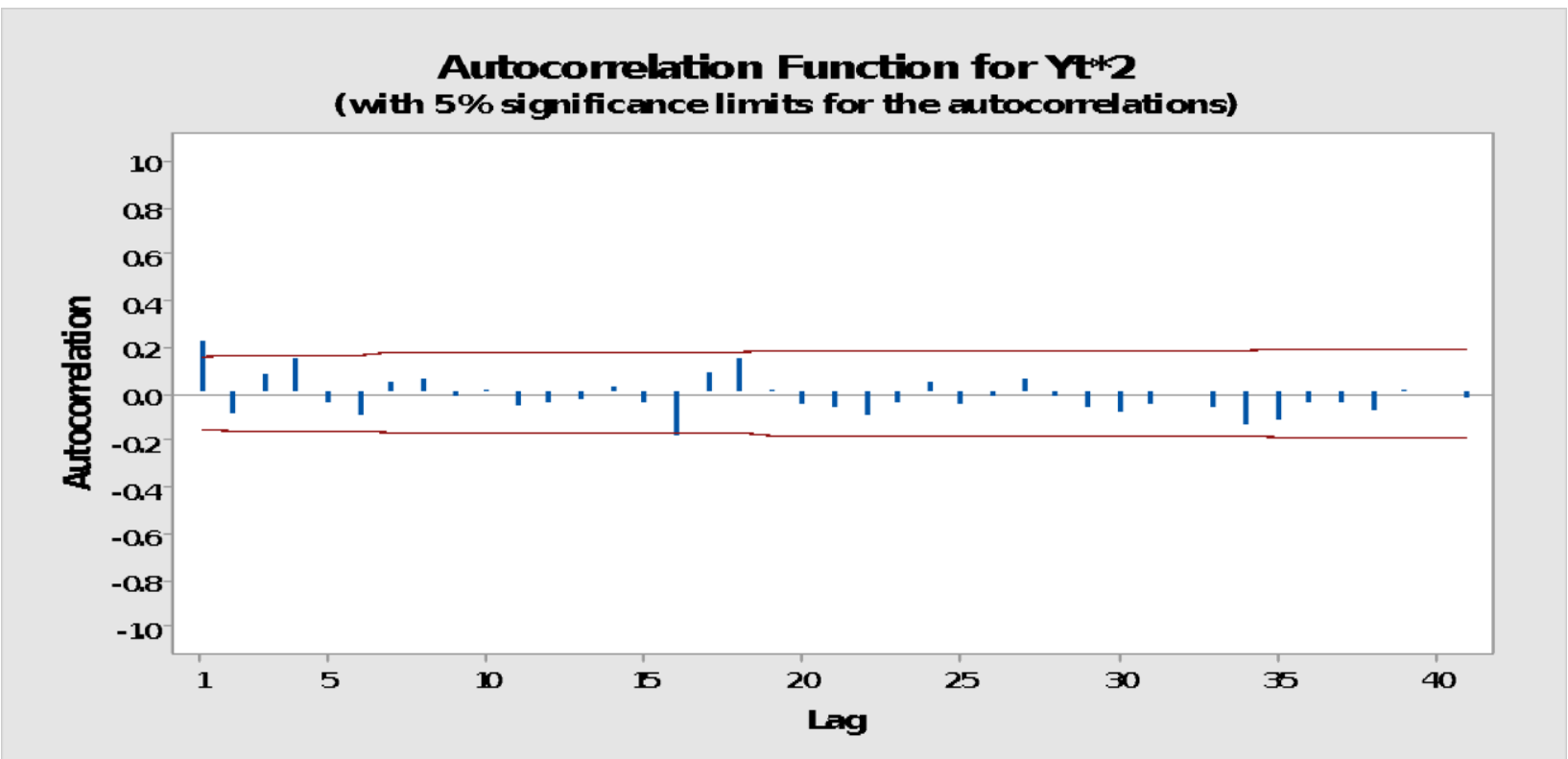

Figure 5: Autocorrelation Function of Crude Oil Production Quantity Volatility 


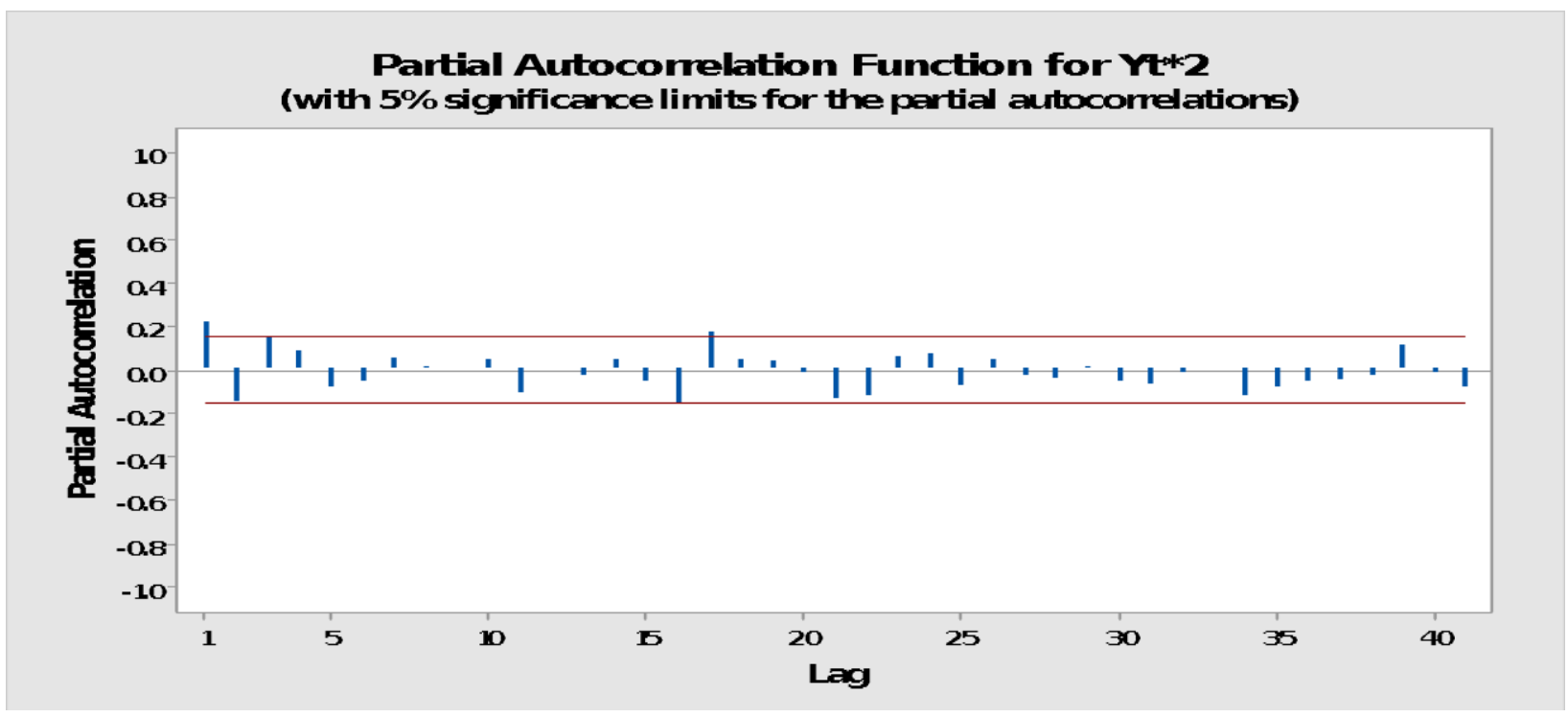

Figure 6: Partial Autocorrelation Function of Crude Oil Production Quantity Volatility

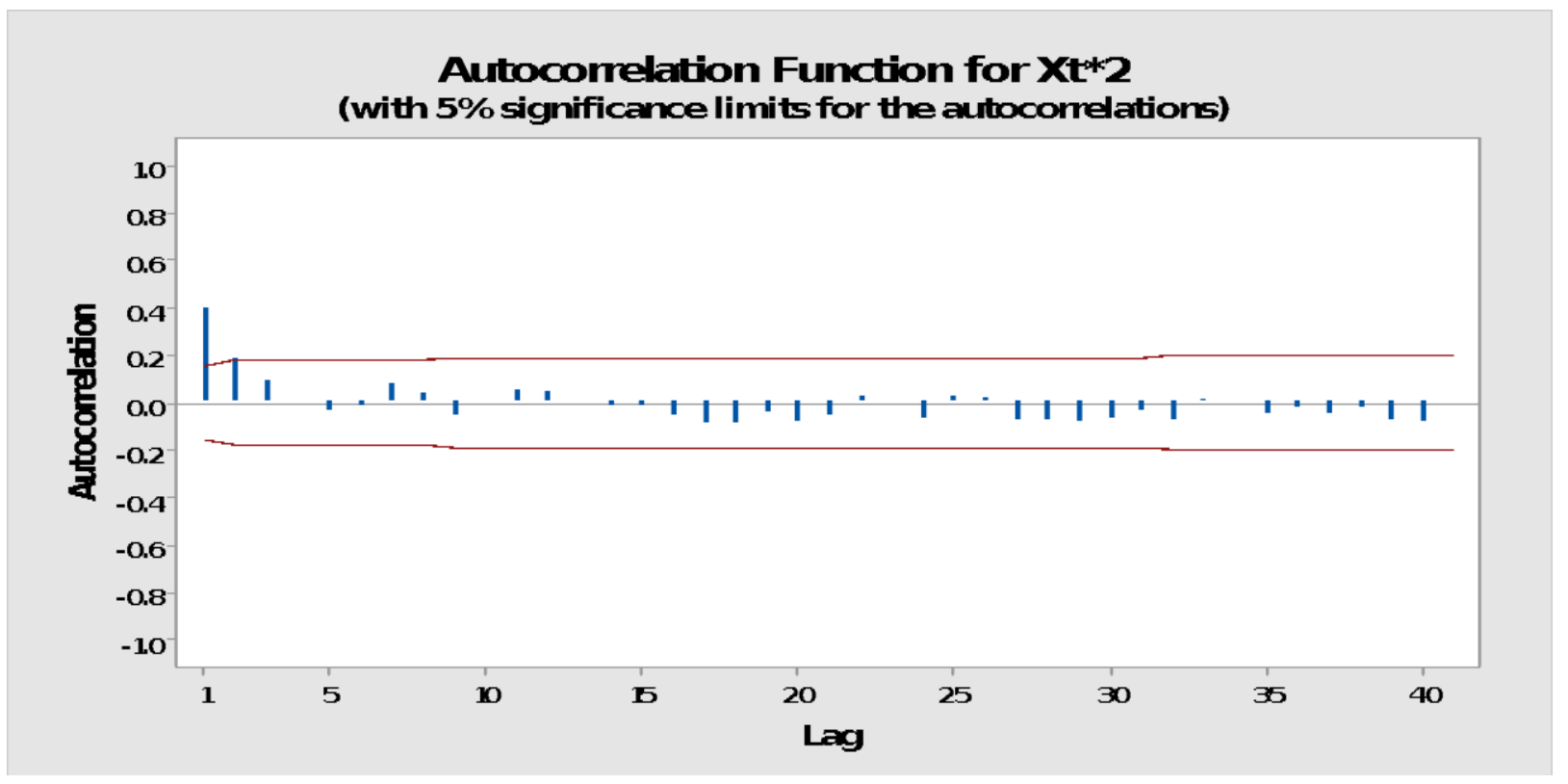

Figure 7: Autocorrelation Function of Crude Oil Price Volatility 


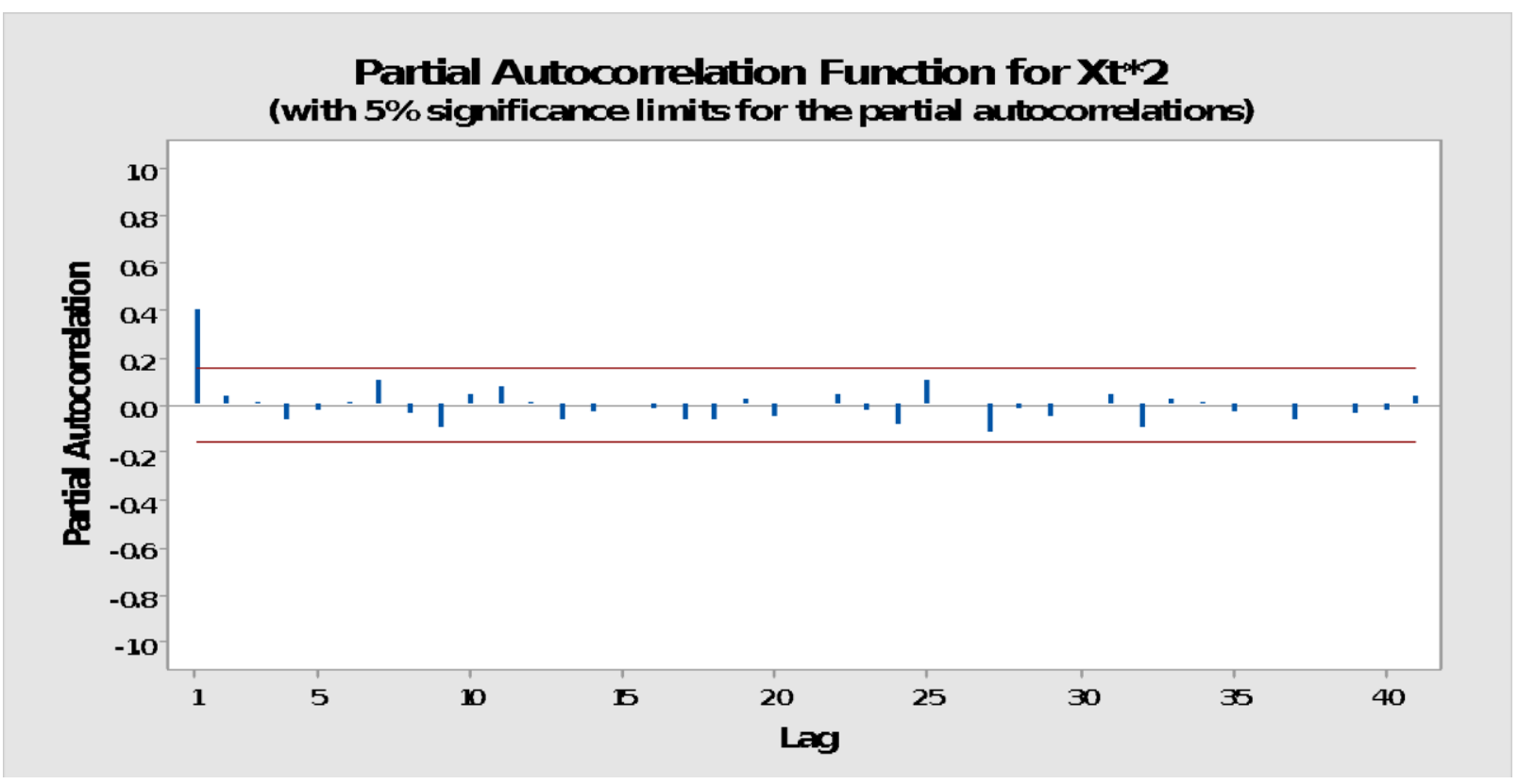

Figure 8: Partial Autocorrelation Function of Crude Oil Price Volatility

Figures 3 and 4 are the trend analyses of stationary crude oil production and prices. Figures 5 , 6, 7 and 8 are the Autocorrelation Functions (ACF) and Partial Autocorrelation Functions (PACF) of crude oil production and price volatilities. The ACF and PACF are useful statistical tools for the choice of the appropriate model and order for a time series that exhibits an autoregressive pattern, a moving average pattern or both.

\section{Granger Causality Test}

Given two-time series variables, say $X_{1 t}$ and $X_{2 t}$, the causality test investigates causation of $X_{1 t}$ to $X_{2 t}$ and $X_{2 t}$ to $X_{1 t}$. It investigates information relevant for the prediction of future values one variable by the other, Granger (1969). Damoder N. and Porter (1997) presented the general VAR as

$$
\begin{gathered}
X_{1 t}=\sum_{i=1}^{2} \alpha_{i} X_{2 t-i}+\sum_{j=1}^{2} \beta_{j} X_{1 t-j}+\varepsilon_{1 t} \\
X_{2 t}=\sum_{i=1}^{2} \gamma_{i} X_{2 t-i}+\sum_{j=1}^{2} \theta_{j} X_{1 t-j}+\varepsilon_{2 t}
\end{gathered}
$$

The above models express interdependence between the two-time series variables and their interactive effects on each other. (16) and (17) are linear combinations of $X_{1 t}$ and $X_{2 t}$ of their lagged terms and the respective predictors. The relationship between the two variables suggests bilateral causality amongst the variables. Bilateral causality means $X_{1 t}$ granger causes $X_{2 t}$ ( $\left.X_{1 t} \rightarrow X_{2 t}\right)$ and $X_{2 t}$ granger causes $X_{1 t}\left(X_{2 t} \rightarrow X_{1 t}\right)$. Hence, the two variables have sufficient information for the prediction of the future values of each other. 


\section{Hypothesis}

$H_{O}$ : The crude oil production quantity does not cause the crude oil price.

$H_{1}$ : The crude oil production quantity granger causes the crude oil price.

$H_{O}$ : The crude oil price does not cause the crude oil production quantity.

$H_{1}$ : The crude oil price granger causes the crude oil production quantity.

\section{F-Statistics}

$$
F=\frac{(R S S R-R S S U R) / m}{R S S U R /(n-k)}
$$

where, RSSR and RSSUR are the regression residual sum of squares restricted and unrestricted, $\mathrm{m}$ is the number of lagged in $X_{1 t}$ or $X_{2 t}$ terms and $\mathrm{k}$ is the number of parameters estimated in the unrestricted regression. $F \sim F_{m, n-k(\alpha)}$. Given the two-time series variables, $X_{1 t}$ and $X_{2 t}$, the regression of $X_{1 t}$ on its lagged terms $\left(X_{1 t-1}, X_{1 t-2}, \ldots, X_{1 t-k}\right)$ and non lagged term of $X_{2 t}$ is known as restricted regression, while the regression of $X_{1 t}$ on its lagged terms $\left(X_{1 t-1}, X_{1 t-2}, \ldots, X_{1 t-k}\right)$ and $\left(X_{2 t-1}, X_{2 t-2}, \ldots, X_{2 t-k}\right)$ is known as unrestricted regression. In a bivariate model, the regression is conducted for both $X_{1 t}$ and $X_{2 t}$ from which RSSR and RSSUR are obtained in each of the cases, Gujarati and Porter (2009).

The following model selection criteria are proposed in this research.

1. Akaike Information Criterion (AIC):

$$
A I C=\ln \ln \left(\frac{R S S}{n}\right)+\left(\frac{2 k}{n}\right)
$$

Where RSS $=$ residual sum of squares, $\mathrm{n}=$ number of observations, $\mathrm{k}=$ number of parameters in the model.

2. Bayesian Information Criterion (BIC):

$$
B I C=n \times \ln \left(\frac{R S S}{n}\right)+k\{\ln (n)\}
$$

where, RSS, $\mathrm{n}$ and $\mathrm{k}$ are as defined as above.

3. Schwartz's Information Criterion (SIC)

$$
S I C=\ln \left(\frac{R S S}{n}\right)+\left(\frac{k}{n}\right) \ln \ln (n)
$$

where RSS, $\mathrm{n}$ and $\mathrm{k}$ are as defined above. 


\section{ANALYSIS AND RESULTS}

In this section, we present the results of different analyses using the aforementioned statistical tools.

\section{Estimation of Variances, Autocovariances and Cross-Autocovariances}

Given the autocovariance $\mathbb{T}_{i t+k, j t+l}(i=1,2 ; j=1,2 ; k=0,1,2 ; l=0,1,2)$, the estimates of the Variances, Autocovariances and Cross-Autocovariances up to lag 2 are presented below;

$$
\mathbb{\Gamma}_{i t+k, j t+l}=\left[\begin{array}{cccccc}
0.000981 & -0.000085 & -0.00048 & 0.000125 & 0.00262 & -0.00021 \\
-0.000085 & 0.001648 & -0.00014 & 0.0000052 & 0.000303 & 0.000168 \\
-0.00048 & -0.00014 & 0.000985 & -0.00049 & -0.000085 & 0.000269 \\
0.000125 & 0.0000052 & -0.00049 & 0.000989 & -0.00014 & -0.000081 \\
0.000262 & 0.000303 & -0.000085 & -0.00014 & 0.001658 & 0.000304 \\
-0.00021 & 0.000168 & 0.000269 & -0.000081 & 0.000304 & 0.001657
\end{array}\right]
$$

The corresponding autocorrelations and cross-autocorrelations are presented as follows,

$$
\mathbb{R}_{i t+k, j t+l}=\left[\begin{array}{cccccc}
1 & -0.49727 & 0.12792 & -0.0669 & 0.20773 & -0.16453 \\
-0.49727 & 1 & -0.50062 & -0.11215 & -0.06666 & 0.21264 \\
0.12792 & -0.50062 & 1 & 0.00401 & -0.11195 & -0.06301 \\
-0.0669 & -0.11215 & 0.00401 & 1 & 0.18288 & 0.10138 \\
0.20773 & -0.06666 & -0.11195 & 0.18288 & 1 & 0.18296 \\
-0.16453 & 0.21264 & -0.06301 & 0.10138 & 0.18296 & 1
\end{array}\right]
$$

The determinant of $R_{i t+k, j t+l}=\left|R_{i t+k, j t+l}\right|=0.4228$

The principal minors of $R_{i t+k, j t+l}$ :

The minor of $R_{i t+k, j t+l}(i=1, k=0 ; j=1, l=0)=0.6231$

The minor of $R_{i t+k, j t+l}(i=1, k=1 ; j=1, l=1)=0.8775$

The minor of $R_{i t+k, j t+l}(i=1, k=2 ; j=1, l=2)=0.5966$

The minor of $R_{i t+k, j t+l}(i=2, k=0 ; j=2, l=0)=0.4623$

The minor of $R_{i t+k, j t+l}(i=2, k=1 ; j=2, l=1)=0.4928$

The minor of $R_{i t+k, j t+l}(i=2, k=2 ; j=2, l=2)=0.4737$

The Positive definiteness property proposed in this work is a test for stationarity of multivariate time series. This is superior to the cointegration test because it can be used to test for the stationarity of multivariate time series with an increasing number of lags. The determinant and principal minor of the autocorrelation and cross-autocorrelation matrix is greater than zero. Hence, the autocorrelation and cross-autocorrelation functions are from multivariate stationary time series. 


\section{Estimation of the Model Parameters}

\section{Estimated model of MARCH (p) and MARCH (q)}

Table 1: Estimates of MARCH (p) and MARCH (q) for $\sigma_{1 t}^{2}$ and $\sigma_{2 t}^{2}$ models.

\begin{tabular}{|c|l|l|l|l|}
\hline Predictor & Coeff. & SE. coeff & T & P-Value \\
\hline MARCH $[p(3,1)]$ for $\sigma_{1 t}^{2}$ & & & & \\
\hline$\sigma_{1 t-1}^{2}$ & 0.4048 & 0.0738 & 5.48 & 0.000 \\
\hline$\sigma_{1 t-2}^{2}$ & -0.1057 & 0.0856 & -1.24 & 0.218 \\
\hline$\sigma_{1 t-3}^{2}$ & 0.2882 & 0.0759 & 3.80 & 0.000 \\
\hline$\sigma_{2 t-1}^{2}$ & 0.0631 & 0.0328 & 1.92 & 0.056 \\
\hline MARCH $[q(1,1)]$ for $\sigma_{1 t}^{2}$ & & & & \\
\hline$\varepsilon_{1 t-1}^{2}$ & & & & \\
\hline$\varepsilon_{2 t-1}^{2}$ & 0.2084 & 0.0459 & 4.54 & 0.000 \\
\hline$\left.\left.\sigma_{1 t-1}^{2} 1\right)\right]$ for $\sigma_{2 t}^{2}$ & 0.0308 & 0.0154 & 2.00 & 0.047 \\
\hline$\sigma_{1 t-2}^{2}$ & 0.393 & 0.159 & & \\
\hline$\sigma_{1 t-3}^{2}$ & 0.130 & 0.184 & 0.70 & 0.482 \\
\hline$\sigma_{2 t-1}^{2}$ & 0.130 & 0.163 & 0.17 & 0.863 \\
\hline$\varepsilon_{1 t-1}^{2}$ & 0.4678 & 0.0706 & 6.63 & 0.000 \\
\hline$\varepsilon_{2 t-1}^{2}$ & & & & \\
\hline MARCH for $\sigma_{2 t}^{2}$ & 0.2787 & 0.0980 & 2.84 & 0.005 \\
\hline$q(1,1)$ & 0.1467 & 0.0329 & 4.46 & 0.000 \\
\hline
\end{tabular}

Table 1 presents estimates of crude oil quantity volatility, $\sigma_{1 t}^{2}$ and crude oil price volatility $\sigma_{2 t}^{2}$. Each of the variances are estimated as autoregressive and moving average processes in the multivariate ARCH models.

$\operatorname{MGARCH}(\mathbf{p}, \mathbf{q}) \sigma_{1 t}^{2}$ and $\sigma_{2 t}^{2}$ models.

Table 2: Estimates of MGARCH $[\mathbf{p}(3,1), \mathbf{q}(1,1)]$ for $\sigma_{1 t}^{2}$ and $\sigma_{1 t}^{2}$ models

\begin{tabular}{|c|l|l|l|l|}
\hline Predictor & Coeff. & SE. coeff & $\mathbf{t}$ & P \\
\hline $\begin{array}{l}\text { MGARCH [p(3, 1),q(1, } \\
\text { 1)] for } \sigma_{1 t}^{2}\end{array}$ & & & & \\
\hline$\sigma_{1 t-1}^{2}$ & 0.3398 & 0.0867 & 3.92 & 0.000 \\
\hline$\sigma_{1 t-2}^{2}$ & -0.1055 & 0.0857 & -1.23 & 0.220 \\
\hline$\sigma_{1 t-3}^{2}$ & 0.2943 & 0.0759 & 3.88 & 0.000 \\
\hline$\sigma_{2 t-1}^{2}$ & 0.0461 & 0.0423 & 1.09 & 0.277 \\
\hline$\varepsilon_{1 t-1}^{2}$ & 0.0733 & 0.0518 & 1.42 & 0.159 \\
\hline$\varepsilon_{2 t-1}^{2}$ & 0.0099 & 0.0179 & 0.55 & 0.580 \\
\hline $\begin{array}{c}\text { MGARCH [p(3, }), \mathrm{q}(1, \\
\text { 1)] for } \sigma_{2 t}^{2}\end{array}$ & & & & \\
\hline$\sigma_{1 t-1}^{2}$ & 0.314 & 0.188 & 1.67 & 0.096 \\
\hline
\end{tabular}


ISSN: 2689-5323

\begin{tabular}{|c|l|l|l|l|}
\hline$\sigma_{1 t-2}^{2}$ & 0.132 & 0.186 & 0.71 & 0.478 \\
\hline$\sigma_{1 t-3}^{2}$ & 0.037 & 0.164 & 0.22 & 0.825 \\
\hline$\sigma_{2 t-1}^{2}$ & 0.4398 & 0.0915 & 4.81 & 0.000 \\
\hline$\varepsilon_{1 t-1}^{2}$ & 0.090 & 0.112 & 0.80 & 0.478 \\
\hline$\varepsilon_{2 t-1}^{2}$ & 0.0171 & 0.0388 & 0.44 & 0.661 \\
\hline
\end{tabular}

Table 2 presents estimates of Multivariate GARCH models for crude oil quantity and price volatilities.

\section{Granger Causality Test}

\section{Case 1:}

$$
\begin{gathered}
F=\frac{(R S S R-R S S U R) / m}{R S S U R /(n-k)} \\
F=\frac{(0.107707-0.099023) / 4}{(0.099023) /(158-9)} \\
F=\frac{0.008684}{0.000645}=13.46
\end{gathered}
$$

$F_{\text {cal }}=13.46$, while $F_{4,139(0.05)}=2.44$. Crude oil production quantity granger causes crude oil price.

\section{Case 2:}

$$
\begin{gathered}
F=\frac{(R S S R-R S S U R) / m}{R S S U R /(n-k)} \\
F=\frac{(0.247826-0.238827) / 4}{(0.238827) /(148-9)} \\
F=\frac{0.00899}{0.001603}=5.61 \\
F=5.61
\end{gathered}
$$

$F_{c a l}=5.61$, while $F_{4,139(0.05)}=2.44$. Crude oil price granger causes production quantity. 


\section{Model Information Selection Criteria}

Table 3: Information Selection Criteria For $\sigma_{1 t}^{2}$ and $\sigma_{2 t}^{2}$

\begin{tabular}{|c|c|c|c|}
\hline $\mathbf{S} / \mathbf{N}$ & Model SPECIFICATION & AIC & SIC \\
\hline \multicolumn{4}{|c|}{$\sigma_{1 t}^{2}$} \\
\hline 1 & $\operatorname{MARCH}[p(3,1)]$ & -13.17 & -13.09 \\
\hline 2 & $\operatorname{MARCH}[q(1,1)]$ & -12.98 & -12.94 \\
\hline 3 & $\operatorname{MGARCH}[p(3,1), q(1,1)]$ & -13.15 & -13.04 \\
\hline \multicolumn{4}{|c|}{$\begin{array}{ll}4 \\
\end{array}$} \\
\hline 1 & $\operatorname{MARCH}[p(3,1)]$ & -11.64 & -11.56 \\
\hline 2 & MARCH $[q(1,1)]$ & -11.47 & -11.43 \\
\hline 3 & $\operatorname{MGARCH}[p(3,1), q(1,1)]$ & -11.61 & -11.29 \\
\hline
\end{tabular}

\section{SUMMARY}

The interest in this paper was to fit multivariate MARCH and MGARCH models to crude oil quantity and price volatilities as well as investigate the effect of each volatility series on another. As presented in figures 1 and 2, the trend analyses of crude oil production quantities and prices exhibited a downward trend in each of the two series, describing a reduction in production quantities and prices for the period under review. The trend analysis of the return series in figures 3 and 4 showed stability in the return series. Figures 5, 6, 7 and 8 are autocorrelation and partial autocorrelation functions of volatility measures of crude oil quantity and price as the basis for the choice and orders of MARCH and MGARCH models. Crossautocovariances and cross-autocorrelations of the return series were obtained for lags 0,1 and 2 of the two series.

The stationarity of the series was investigated through a cointegration test. This involved the initial unit root tests on individual time series using the Dickey-Fuller method. The results obtained showed that crude oil production quantity and crude oil price have unit roots, meaning they are nonstationary. A Cointegration test was then performed using the Dickey-Fuller test. The result obtained shows that the linear combination of the two series have a long-run relationship and are cointegrated at $I(0)$. This confirms the stationarity of the series. A successful test for stationarity involving the investigation of the positive definiteness property of multivariate time series was adopted. The computations of principal minors and determinant revealed the matrix of the autocorrelation and cross-autocorrelation was positive definite, confirming the stationarity of the multivariate time series.

MARCH, MARCH $[p(3,1)]$, MGARCH $[p(3,1), q(1,1)]$ were fitted to volatility measures of crude oil production and price. The model parameter estimates are presented in tables 1 and 2 , with " $\mathrm{t}$ " and " $\mathrm{p}$ " values indicating significant and insignificant parameters. MARCH [q (1, 1)] for crude oil production and crude oil price showed significant effects of interactions between the squared errors of crude oil production and price on each conditional variance. The estimates in the MARCH and MGARCH models indicate interactions and interdependence between the predictor and response, hence, the suitability of the two sets of models. The Granger Causality tests revealed bilateral causality between crude oil production and price. 
This further explains the feedforward and feedback mechanisms between crude oil production and price. The Akaike Information Criterion (AIC) and Schwarz's Information Criterion (SIC) were used for model comparison. From the results of table 3 as obtained in table 13. MARCH is the best model for crude oil production and prices.

\section{CONCLUSION}

There is no disputing the fact that every nation has its own unique economic challenges, especially when experiencing ups and downs in some economic sectors. Despite the advocacy and the government's effort towards economic diversification, Nigeria is still bedevilled by a huge reliance on petroleum resources as the major factor of economic growth and sustainability. The importance of crude oil production quantity and price can not be overemphasized in view of the role the two macroeconomic variables jointly play in the nation's economic development. The interactions and interdependence of crude oil production and price volatilities as established in this, bring to focus clear evidence of the joint contributions of the two macroeconomic variables to the nation's economic development. The research has revealed mutual effects of crude oil production and price on each other. The two variables have sufficient information to predict future values of each other. This paper recommends constant and consistent investigation of production quantity and addressing the challenge of volatility as a way forward to cushioning the effects of the economic crisis during the regime of crude oil price shocks.

\section{REFERENCES}

Babtunde S, Omotosho and Sani I. Doguwa (2012): Understanding the dynamics of Inflation in Nigeria; A GARCH Perspective. CBN Journal of Applied Statistics, Volume 3, NO.2 pp 51-74

Bala D. A. and Asemta J. O (2013): Exchange rate volatility in Nigeria: application of GARCH models with an exogenous break. CBN Journal of statistics 4(1)

Bala, D. A. \& Takimoto, T. (2017). Stock markets volatility spill-overs during financial crises: A DCC-Multivariate GARCH with skewed-t density approach. Borsa Istanbul Review, 17(1), 25-48.

Bollerslev, T (1986). Generalized autoregressive conditional heteroscedasticity. Journal of Econometrics, 31, 3, pp.307-327

Bollerslev, T (1990). Modelling the Coherence in short-Run Nominal Exchange Rates. A Multivariate Generalized ARCH Model. The Review of Economics and Statistics. Vol. 72, No.3, 498-505.

Bollerslev, T., Engle, R.F. and Wooldridge, J.M. (1988): A capital asset pricing model with time-varying covariance. The Journal of Political Economy,96: 116-131.

Box G.P and Jenkins, G.M: (1976) Time Series Analysis, forecasting and control, Holden days san Francisco.

CBN Statistical Bulletin, Central Bank of Nigeria, Abuja. 2019;21.

Claudia K. (2004): The COGARCH: A review with news on option pricing and Statistical Inference: SSRN Electronic journal

Damoder, N. G and Dawn, C. P (1997): Basic Econometrics. Fifth edition, pp 792-793. 
David Ndwiga and Peter Muriu (2016): Stock Returns and volatility in an emerging equity market. Evidence from Kenya. European Scientific Journal 12(4).

Deebom, Zorle Dum \& Isaac Didi. (2017): Modelling price volatility of Nigeria crude oil markets using GARCH models. 1987-2017. International Journal of Applied Science andMathematical theory, ISSN 2489-009x. Vol. 3, No.4

Ding Z. (1993): A long memory property of stock market returns. Journal of Empirical Finance, pp, 80-106

Emenike Kalu O. (2017): The Interrelationship between Crude oil price volatility and money market rate volatility in developing oil-producing economy. Eastern European business and journal. Vol 3, no.1, pp 28-47.

Engle, R. F, and Kroner, K. F (1995): Multivariate Simultaneous Generalized ARCH. Econometric Theory, volume 11.

Engle, Robert F (1982): Autoregressive Conditional Heteroscedasticity with Estimates of the Variance of United Kingdom Inflation. Econometric Society, vol. 50 (4) pages 9871007

Franses, P. H. and McAleer, M. (2002). "Financial Volatility: An Introduction", Journal of Applied Econometrics, 17:419-424

Glosten, L, R., Jagannathan, R. \& Runke, D. E (1993): On the relationship between the expected value and the volatility of the nominal excess returns on stocks. Journal of Finance, 48, PP, 1779-1801

Granger, C. W. J (1969): Investigating causal relations by econometric models and crossspectral methods. Econometrica, pp 424-438

Gujarati, D. N. and Porter, D. C. (2009). Basic Econometrics (5th ed.)

Ifeanyi O. Nwanna, Ayenajeh M., Eyedayi (2016): Impact of crude oil price volatility on economic growth. IOSR Journal of Business and Management, Vol, 18, Issue 6, pp 1019

Isenah, M. Godknows, Agwuegbo, S.O.N and Adewoke, A.P. (2013): Analysis of Nigerian stock market return volatility using skewed ARMA-GARCH model. Journal of Nigerian Statistical Association, Volume 25.

Kiyang Y. and Shahabi C. (2005). On the stationarity of multivariate time series for correlation-based data analysis. ICDM '05' Proceedings of the fifth IEEE International Conference on Data Mining, pp. 805-808.

Koima J.K, Mwita P. N and Nassuma, D.K (2015): Volatility estimation of stock prices using GARCH method. European journal of business management. volume 7, no.19

Kraft, R. Engle (1986): Generalized Autoregressive Conditional Heteroscedasticity. Journal of Econometrics. Vol.31, issue 3

Narayan P., and Narayan, S. (2007). Modelling Oil Price Volatility. Energy Policy

Nelson, D.B (1991). Conditional heteroskedasticity in asset returns: A new approach. Econometrica, 59, pp,347-370 No. 35,

Nortey, E. N., Ngoh, D. D., Doku-Amponsah, K. \& Ofori-Boateng, K. (2015). Modelling inflation rates and exchange rates in Ghana: Application of Multivariate GARCH models

Olowe R. A. (2009): Oil price volatility and the Global Financial Crisis. Paper presented at 9th Global Conference on Business \& Economics, Cambridge University, UK.

Olugbenga F. and Kehinde O. S. (2017), Modeling the Impact of Oil Price Volatility on Investment Decision marking in marginal field's Development in Nigeria. British Journal of Economics, Management and Trade. 17 (1): 1-16, 2017; Article No. BJEMT.28175 
Omotosho B. S. and Doguda S. I. (2012): Understanding the Dynamic Inflation Volatility in Nigeria: A GARCH perspective. CBN Journal of Applied Statistics 3(2) 51.74

Patrick, M. (2020). Properties of the power envelope for tests against both stationary and explosive alternatives: The effect of trend. Journal of Time Series Analysis, 41(1): 146153.

Philip O, Wolfgang, S, \& Robert, G (2018): Generalized Spatial and Spatiotemporal Autoregressive conditional heteroscedasticity. Spartial Statistics, 26, pp,125-145.

Philip, I. N. and Adeleke, O. (2017): Determinants of FDI and FFI volatility; An E-GARCH Approach. CBN Journal of applied statistics,8,2, pp 47-67.

Roni Bhowmik and Shouyang Wang (2020): Stock Market Volatility and Return Analysis: A Systematic Literature Review. Entropy 22.

Roy Van der Weide (2002): GO-GARCH: A Multivariate Generalised Orthogonal GARCH Model. Journal of Applied Econometrics, Vol.13, No.5; 549-564.

Sentana, E (1995). Quadratic ARCH models. Review of Econometric Studies, 62. Pp, 639661

Suliman Z. S (2012): Modelling exchange rate volatility using GARCH models: Empirical evidence from Arab Countries. International journal of econometrics and finance vol.4 no.3

Tatyana V. A. and Marc G. (2010): Cross- Variance functions for multivariate random fields based on latent dimensions biometrics. 97(1), pp15-30

Usoro A. E (2020): On the stationarity of multivariate time series analysis. Benin Journal of Statistics. Vol.3. pp160-169.

Usoro A. E, Awakessien C. E and Omekara C. O (2019): Special Classes of Multivariate Generalized Conditional Heteroscedasticity models for volatility series. Journal of the Nigerian Statistical Association, Vol.31, pp 39-52.

Usoro, A. E., Ikpang, N. I. and George, E. U. (2020): Volatility Measure of Nigeria Crude Oil Production as a Tool to Investigate Production Variability, African Journal of Mathematics and Computer Science Research, 13(1), 1-16

Venables, W.N and Ripley, B.A (2002): Auto and cross-covariance and correlation function, fourth edition, springer -Verlag

Zakoian, J.M (1994): Threshold heteroscedasticity models. Journal of econometric dynamics and control pp 931-955 